\title{
PROVOCAIACCIONES URBANAS \\ Tácticas ascendentes y creativas en el Centro Histórico de Córdoba, Argentina
}

\author{
Dr. José Ignacio Stang \\ Institución de pertenencia: CIECS (CONICET y UNC) \\ Director de tesis: Dr. Horacio Gnemmi Bohogú \\ josestang@conicet.gov.ar
}

\section{RESUMEN}

Se explora y analiza la irrupción y despliegue de ciertas acciones artísticas creativas en y con el espacio urbano público del Centro Histórico de la ciudad de Córdoba, Argentina en la actualidad. Desarrolladas por agentes sociales pertenecientes al ámbito de las economías creativas, las prácticas indagadas constituyen un conjunto de acciones que conllevan un carácter efímero y transitorio y que permiten, además, la posibilidad de realizar una lectura integrada respecto de las inestabilidades en la ciudad contemporánea.

Lo que se presenta, conforma la síntesis de una investigación doctoral finalizada, por lo que solo se expone la descripción, fundamentación y justificación de la elección del tema-problema junto a un resumen de tres casos analizados que buscan corroborar la teoría emergente expuesta sobre un escenario específico.

Palabras claves: espacio urbano público, creatividad, acciones efímeras, tácticas ascendentes

\begin{abstract}
It explores and analyzes the irruption and deployment a kinf of creative artistic actions in and with the urban public space of the Historic Center of the city of Cordoba, Argentina at present. Developed by social agents belonging to the field of creative economies, the practices investigated constitute a set of actions that entail a transitory and ephemeral character and that allow, in addition, the possibility of carrying out an integrated reading respect to the instabilities in contemporary city.

What is presented forms the synthesis of a finished doctoral research, so only the description, foundation and justification of the choice of the problem-topic is exposed, along with a summary of three analyzed cases that seek to corroborate the emerging theory exposed in a specific setting.
\end{abstract}

Key words: urban public space, creativity, ephemeral actions, bottom-up tactics 


\section{INTRODUCCIÓN}

Nuestro discurso cotidiano (el de los arquitectos) refiere, en parte, a cuestiones relativas o inclusivas de la ciudad y, más específicamente, a sus espacios de uso común donde confluyen nuestras prácticas, encuentros y desencuentros. Con menor frecuencia, pero no por ello menos importante, se habla también de la ciudad actual y sus espacios urbanos públicos en su relación con la creatividad y el arte. Si bien existen actividades notorias que se destacan por su creatividad aplicada, no hay actividad humana que no esté exenta de crear (Wagensberg, 2017).

En el discurso contemporáneo se asumen, de manera práctica y al hablar del carácter y la realidad de los ámbitos mencionados, una serie de presupuestos y preconceptos que generan la representación y construcción de ciertos límites. Dicha actitud acota nuestras vidas cotidianas y provoca un efecto negativo por no ayudar en el necesario proceso de comprensión de aquellos aspectos críticos de la realidad. Llegar a reconocer el carácter de los límites, tantas veces arbitrario, sería ya un avance, y resulta un desafío que debiéramos proponernos (Latouche, 2014), entendiendo además que el límite no es un punto donde una cosa finaliza, sino un punto de partida desde donde comienza la propia esencia e inicia lo que es colocado dentro de sus límites (Di Felice, 2012).

La ciudad, vista desde los presupuestos y preconceptos referidos, pareciera ser asumida solo como un espacio que habitamos, como una construcción arquitectónica y urbanística en un espacio más o menos determinado y limitado. Sobre ella se proyecta la historia de una comunidad móvil y los discursos institucionales que tienden, en el mejor de los casos, a un embellecimiento o, muchas veces, a una adecuación de su imagen con tendencia a una espectacularidad. Sobre los espacios urbanos de uso común, habitualmente denominados espacios públicos, una primera consideración, apoyada en una visión estatal en nuestras sociedades latinoamericanas, parte de la diferenciación entre la vida pública y la vida privada, es decir, entre la administración del espacio por parte del Estado y la vida cotidiana de la sociedad en su intimidad. Desde estos y otros supuestos, transitamos la ciudad y la transformamos, sin que mute mayormente aquella noción primera de ciudad que describe el espacio que está por fuera de nuestra vivienda, el público, simplemente como aquel por el que necesariamente debemos transitar para ir desde un punto a otro. Si bien la anterior afirmación puede parecer la descripción de una aproximación empírica un tanto inocente, no deja de constituirse como el lugar común desde donde inicialmente suele pensarse la ciudad.

En relación a la creatividad, se debe tener la precaución de establecer que no todo vale bajo el amplio y ambiguo paraguas que acoge las ideas (Wagensberg, 2017). En este sentido, la creatividad implica siempre una preocupación por el mundo de las ideas, pero no significa que todo lo que sea crea sea importante o trascendente. Sobre los aspectos referidos a la creatividad y al arte, frecuentemente se construyen aproximaciones iniciales más o menos inocentes, ingenuas, ligeras e interesadas que, por lo general, se sostienen con un hablar cercano a la crítica, ya que todos en mayor o menor medida somos críticos y artistas (Groys, 2016). Sin embargo, cuando la proximidad de la experiencia es mayor (al involucrarnos e incluir a la ciudad en su génesis), la crítica se proyecta y construye sobre lo contemporáneo. Uno de los resultados más habituales es el de un desconocimiento de dicha realidad, en el que se disputan y apelan categorías, se emiten juicios inestables y por momentos contradictorios. Prevalecen así, formas y conceptos poco operativos y un tanto obsoletos para hacer referencia a ciertas prácticas contemporáneas creativas, que son referidas comúnmente solo como un despliegue de creatividad de arte sobre y en el espacio urbano público de la ciudad. Así, la ausencia de elementos con los que resulte posible poder encontrar y establecer referencias estimula la continuidad de los mismos conceptos y por lo tanto de los mismos análisis.

La realidad contemporánea establece una línea entre el notable espesor del pasado y la inmensidad interrogativa del futuro. La línea, definida por el presente, es asumida hoy como un tiempo instantáneo y fugaz que se hace manifiesta en cada gesto y acto llamado a contar o hacerse notar. La inseguridad del presente y la incertidumbre sobre el futuro incuban y crían nuestros temores, y nos encuentran carentes de las herramientas que permitan reconquistar el control de lo fugaz (Bauman, 2011). A lo instantáneo se le suma, además, la mutación, el cambio, como una frecuente temática del momento. Se alienta y desea el cambio y todo lo que está relacionado con él, aunque muchas veces puede ser simplemente un primer entusiasmo, más intelectual que vivencial (Llamazares, 2013). Como contrapartida frente a tal cambio, se presenta la tradición, que se constituye, la mayoría de las veces, a partir de una especie de detalle histórico que se adhiere al presente, envuelto en alguna clase de bandera. El pasado viaja en el presente en tránsito hacia un tiempo utópico. En su paso por el presente, la tradición impacta contra el cambio, con el que no siempre dialoga. Como consecuencia, suele surgir una actitud de desconcierto primero y de provocación luego. 
En la expresión de la conjunción e interrelación entre tradición y cambio se manifiesta, como representación de dicho vínculo en la ciudad, la centralidad histórica. Asumido como espacio urbano público, el Centro Histórico (en adelante, $\mathrm{CH}$ ) congrega multiplicidad y diversidad de prácticas, expresiones históricas y el despliegue e interacción de distintos agentes sociales. Concepto y objeto, el $\mathrm{CH}$ es asumido como un espacio que incluye fenómenos diversos y que, en la inmediatez de la actualidad, constituye una forma de comunicación e intercambio de información (Carrión 2013; 2008). Opera como un espacio simbiótico, en donde confluyen percepciones y vivencias distintas a partir de símbolos construidos en distintas etapas de la historia y expuestos en sus diferentes capas de la memoria (Gnemmi, 2014). La realidad del CH se presenta en la contemporaneidad como un reto vinculado a distintas variables, donde a partir de una búsqueda en la revalorización de la centralidad histórica como tal, se plantea el desafío de desarrollar nuevas metodologías, técnicas y conceptos que abran nuevas perspectivas analíticas y mecanismos de intervención. Es por ello que es necesario comenzar a evaluar e indagar nuevas maneras en la aproximación a su estudio, no solo desde lo físico-material, sino también desde los actores y prácticas desplegadas en sus espacios. El cambio frente a la tradición, en un diálogo imprevisto, se expresa y muestra en las centralidades históricas desde distintas y diversas formas. En algunos casos, esa expresión se manifiesta como una provocación al transeúnte a partir de acciones urbanas artísticas y creativas. Desde la excepcionalidad, irrumpen en el ritmo cotidiano, presentando alternativas diferentes de uso y significado y, por lo tanto, necesarias también de ser indagadas.

El presente trabajo expone una aproximación sobre la búsqueda anunciada. Representa la síntesis de una tesis doctoral concluida que desarrolla y explora, a través de una lectura integrada, las inestabilidades de la ciudad contemporánea (leída desde la centralidad histórica de la ciudad de Córdoba, Argentina, como espacio urbano público) y la excepcionalidad transitoria de ciertas acciones efímeras (tácticas ascendentes desarrolladas por agentes sociales pertenecientes al ámbito de las economías creativas).

Estructuralmente, el desarrollo del trabajo se divide en tres apartados. El primero, la provocación, aborda la descripción, fundamentación y justificación de la elección del tema-problema. El segundo, las acciones, expone un resumen de los tres casos analizados en la tesis, para buscar dar cuenta sobre terreno específico de aquellas prácticas descriptas de manera teórica en instancias anteriores. El último apartado expone las conclusiones.

La hipótesis inicial propuesta supone que la irrupción excepcional de provoca/acciones urbanas en el espacio urbano público del $\mathrm{CH}$ de la ciudad de Córdoba en la actualidad instala una dualidad entre lo real-edificado y lo ficcional-momentáneo en las dimensiones espacio-temporales, en un intento de reclamar la ciudad para redefinir los límites del espacio común habitado, promocionando la producción de un tipo de espacio diferente. Se piensa, además, que la excepcionalidad urbana generada a partir de dichas tácticas ascendentes y creativas propone la habitación de espacios y tiempos intermedios, lo que provoca intersticios urbanos en una transformación dinámica a partir de elementos formativos de prácticas sociales, a la vez que se experimentan y conceptualizan espacialidades que contribuyen a relaciones sociales distintas. El desarrollo de estas prácticas propone una ciudad de ciudades, donde emerge una creatividad y arte de carácter colectivo y se combinan esfuerzos orientados a la creación de una cultura pública emancipadora, creadora de vínculos solidarios con la otredad y con nuevas formas de vida en común.

Explorar y analizar el accionar de aquellas prácticas desarrolladas como provoca/acciones en el $\mathrm{CH}$ de la ciudad de Córdoba se presenta como uno de los tantos caminos posibles para aproximarse al desafío de construir nuevas miradas y maneras de abordar y estudiar a las centralidades históricas. Estas resultan relevantes, además, como búsquedas para la comprensión de los intercambios y préstamos que se suceden en la lectura de la ciudad actual desde lo urbano público, ya no exclusivamente sobre la distinción o definición de lo público, sino también sobre la apropiación que la ciudadanía ejerce sobre ello (Han, 2016). El despliegue de estas excepcionalidades señala, además, un tipo específico de acción que se caracteriza por un desarrollo de temporalidad efímera, transitoria y fugaz. Desplegadas en un espacio urbano público particular, como lo es el del $\mathrm{CH}$, a través de un carácter provocativo, producen el desarrollo de un sistema de relaciones entre la acción, los agentes sociales participantes y el entorno construido implicado. Distante de subordinar un campo a otro, espacio, actores y acción, se persigue, por el contrario, dar respuesta a la necesidad de integrar y complementar dichos aspectos a través de una reflexión crítica sobre y desde la ciudad (a través de sus espacios urbanos públicos del $\mathrm{CH}$ ), entendida más como una construcción estética y móvil (donde se despliega la realización e interacción de ciertas prácticas artísticas creativas contemporáneas) que como un hecho físico o un escenario fijo y estático y, en consecuencia, intocable e inamovible. 


\section{LA PROVOCACIÓN}

La elección del tema tiene su génesis en una búsqueda de aproximación al entendimiento de la ciudad de Córdoba en la contemporaneidad, desde la exploración y el estudio de su dinámica urbana actual. Se decidió, como primer abordaje, estudiarla a través de los espacios urbanos públicos debido a que, como lugares comunes y compartidos, se considera que es a través de ellos donde la ciudad se desnuda, expone y expresa. Frente a la complejidad y dimensión de tan ambicioso objetivo, se eligió focalizar la mirada en aquellos espacios urbanos públicos pertenecientes al área central, más específicamente en aquellos pertenecientes y conformadores del $\mathrm{CH}$ de la ciudad. La justificación del recorte mencionado corresponde en primera instancia a la consideración de que en nuestras sociedades latinoamericanas se está viviendo en la actualidad una revalorización de la ciudad construida y sus centralidades y, dentro de ella con un grado aún mayor, una revalorización de dos tipos de centralidad: la histórica y la urbana-funcional (Carrión, 2001). En algunos casos, como en el de Córdoba, estas centralidades coinciden y se superponen.

Con el regreso de la prioridad a la urbe construida, el $\mathrm{CH}$ como centralidad urbana particular cobra un peso singular y su naturaleza cambia (Carrión, 2008) y, por lo tanto, las formas, caminos y aproximaciones para observarlo, estudiarlo y analizarlo deben acompañar también al cambio. $\mathrm{El} \mathrm{CH}$, asumido como espacio urbano público, es un ámbito simbólico. Dicho simbolismo se concentra en el tiempo y el espacio, ya que es uno de los ámbitos más significativos y representativos en la ciudad, a tal punto que puede alcanzar a imprimir el carácter de la urbe toda.

Al hacer una primera aproximación de carácter vivencial al escenario de estudio, transitando y recorriendo los espacios urbanos públicos del $\mathrm{CH}$ de la ciudad de Córdoba, se observó como factor común en muchos de sus espacios una serie de excepciones a la tradición, expresadas a través de prácticas y acciones efímeras. Formuladas a la manera de relatos urbanos y prácticas simbólicas, las acciones observadas parecían dejar ciertas marcas cualitativas distintivas de una relación con el entorno, lo que propone una imagen de la ciudad no solo heterogénea, sino que también reconocida en la experiencia y el recorrido. En su temporalidad de ejecución transitoria o efímera, accionadas con un marcado carácter provocativo, estas prácticas establecen un particular uso espacial y, por lo tanto, se convierten en una temática rica de abordar, ya que ofrece posibilidades de exploración e indagación. En este sentido, cobra relevancia y riqueza el diálogo inesperado, imprevisto y sorpresivo en la dualidad establecida entre tradición-cambio y efímero-permanente, es decir, entre lo transitorio y fugaz de la acción y su conjugación con lo edificado, mostrado como aquello más estable y constante a través de las distintas capas de la memoria asentadas en la cualidad y simbolismo de las centralidades históricas.

Al carácter de tales acciones se lo identificó como táctica (De Certeau, 2010) por ser una práctica efímera, inesperada, sorpresiva, a diferencia de las estrategias, vistas como acciones de poder sobre el territorio desde la planificación, el gobierno, en un sentido que podría ser asumido como la visión de alguien que mira desde arriba hacia abajo. Además, se les asignó también un marcado carácter ascendente entendido como parte de un sistema emergente complejo (Johnson, 2003), diferente del carácter descendente, desde arriba hacia abajo, como sistema institucionalizado y jerarquizado. La complejidad y el desarrollo de sistemas complejos urbanos (Reynoso, 2010) se asumen en este sentido como una sobrecarga sensorial de estímulos sobre sus habitantes, pero, además, como la capacidad posible de autoorganización a partir de sus interacciones locales cotidianas.

Realizadas por diversos agentes sociales pertenecientes a las artes visuales, plásticas, la arquitectura, el diseño, la comunicación social, la gestión cultural, entre otros, dichas tácticas suelen recibir variedad de denominaciones: acciones, obras, intervenciones, instalaciones, performances, site specific, esculturas, happening, acciones urbanas, entre otros términos posibles. Todos tienen ciertas diferencias entre unos y otros pero, en definitiva, se unifican al ser asumidos como prácticas con un marcado carácter creativo y desplegadas sobre el espacio urbano público en una actitud de acción y reacción. Debido a la limitación y recorte propuestos para la investigación doctoral, al abordar dichos grupos y sus prácticas en su complejidad y heterogeneidad, se hizo necesaria la búsqueda de un concepto como perspectiva posible desde donde indagarlos, agruparlos y limitarlos para poder acceder al estudio de estas acciones desde ciertos parámetros. Se decidió, a partir de un análisis e indagación inicial donde se leyó quiénes eran los agentes sociales involucrados, los espacios donde desarrollaban sus prácticas, intereses, proveniencia, profesiones, etc., la elección del emergente concepto de economías creativas (Cunningham, Banks y Potts, 2008), para agrupar acciones y actores diversos y variados. Si bien el término economía creativa fue popularizado por Howkins (2001), los autores mencionados profundizan el concepto y la definen como "(...) un complejo sistema que obtiene su 'valor económico' a partir de la facilitación de la evolución económica, un sistema que produce 
atención, complejidad, identidad y adaptación a través del recurso primario de la creatividad" (traducción propia de Cunningham, Banks y Potts, 2008:17). Es difícil alegar, por lo tanto, que todos los aspectos de la creatividad económica, social o política son generados únicamente (o incluso, principalmente) por los procesos mismos de las industrias culturales y creativas. Por este motivo, siguiendo lo pautado por el PNUDUnesco (2013), el término economía creativa será utilizado en esta investigación de manera más abarcadora y en relación con aquellas actividades que impliquen creatividad cultural e innovación. Si bien el concepto tiene rasgos, características e implicancias posibles de ser discutidas, debido al rol y tiempo establecido para esta investigación, no se consideró pertinente abordar este problema. Se priorizó indagar en la excepcionalidad de las propias acciones, sus actores, el desarrollo de ellas en el espacio, la interacción con los ciudadanos y las consecuencias sobre la ciudad, es decir, estudiar y analizar la excepcionalidad de estas prácticas como promotoras, posibles o no, de una urbanidad alternativa y complementaria.

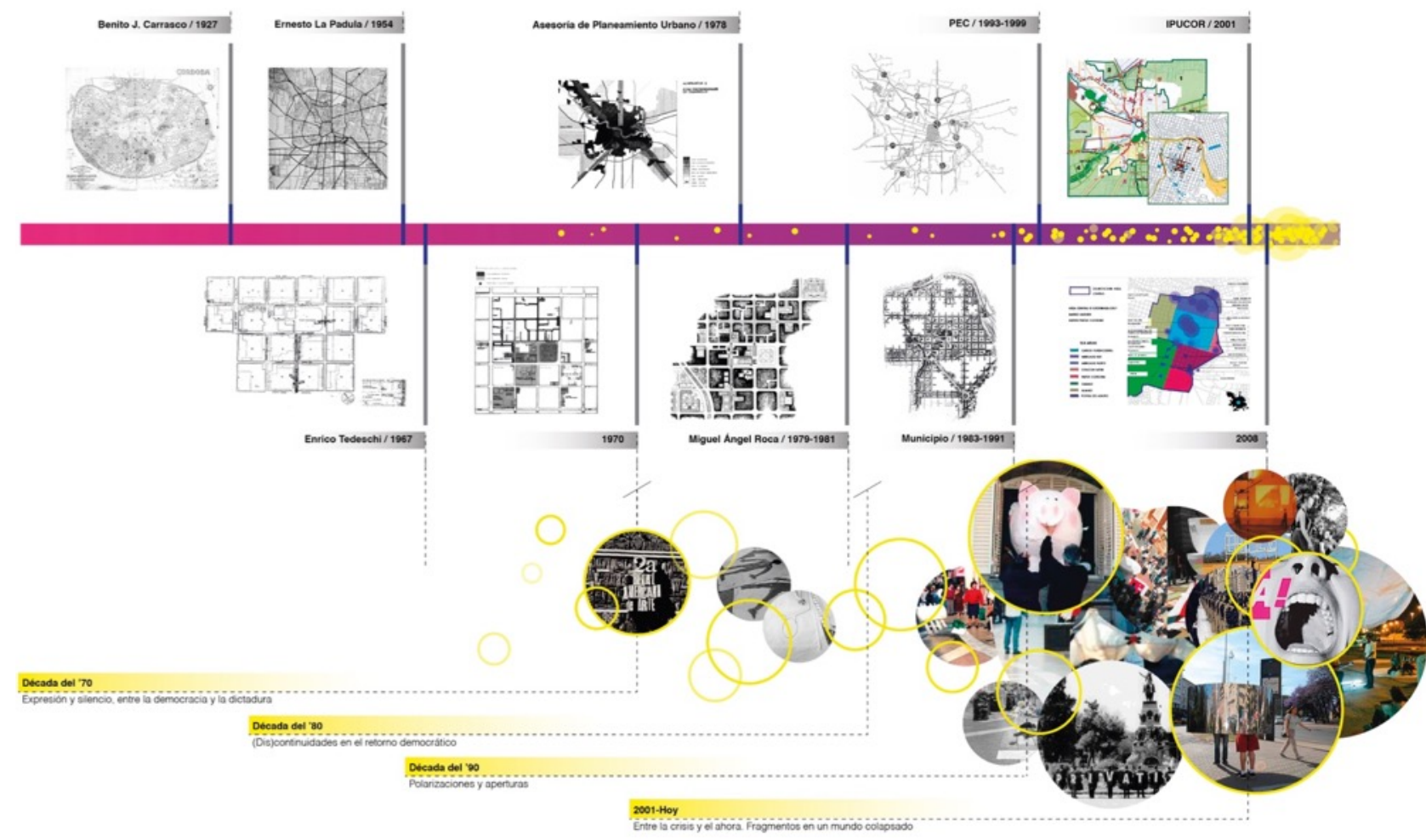

Construcción de una posible infografía histórica que evidencia permanencias y cambios en la construcción del objeto CH a partir de dos grandes grupos de análisis: estrategias y tácticas.

Fuente: Elaboración propia

La comprensión de la urbanidad como objetivo de las ciencias sociales posee diversos enfoques y presenta una serie de divergencias de carácter epistemológico, teórico y metodológico (Lange Valdés, 2015; Gravano, 2013; Torres, 2003). Interesa en estas disonancias, para un abordaje inicial, el encuentro de un punto de convergencia: el reconocimiento fundamental de la relevancia que las prácticas sociales urbanas tienen como productoras de urbanidad y su importancia para la creación, transformación y apropiación del espacio urbano público. El ser humano es un animal social que se debate permanentemente entre una única identidad individual (él mismo) y varias identidades colectivas (barrio, ciudad, tribu, clan, club, nación, etc.) (Wagensberg, 2017). En este sentido, focalizar la atención en las prácticas sociales urbanas permite acceder al potencial creativo e innovador de la urbanidad, avanzar más allá de la institucionalidad de los procesos formales en el desarrollo urbano y vislumbrar sus dimensiones instituyentes. Los desafíos vigentes planteados para las sociedades del conocimiento resaltan, en este sentido, la necesidad de revalorizar el conocimiento, la innovación y la creatividad como componentes cotidianos en la vida social urbana. Toman así relevancia aquellas perspectivas de abordaje que hacen referencia a las prácticas urbanas cotidianas.

La vinculación entre tácticas ascendentes y economías creativas, como irrupción en las prácticas urbanas cotidianas, permite apuntar a un enfoque crítico y reflexivo en la medida que promueven la observación, visibilidad y reconocimiento de aquellos intereses, negociaciones, intercambios y acuerdos no necesariamente explícitos en torno a su formulación y desarrollo urbano. Se evidencia su carácter político y, por lo tanto, también de producción espacial. El surgimiento de ciertas eventualidades y vulnerabilidades, como el actual calentamiento global (económico, social, político y ecológico), ponen en entredicho la 
sostenibilidad y el impulso de grandes proyectos urbanos. Estas contingencias destacan la necesidad y relevancia de promover enfoques críticos y reflexivos que atiendan a las condiciones y desarrollo del complejo contexto territorial actual.

El espacio urbano público, territorio soporte y parte de las acciones a indagar, se asume como espacio de representación. Se puede leer en él la representación del poder, de sus instituciones y símbolos, la representación social de los ciudadanos, de su historia común y de sus intereses ordinarios, y finalmente, la representación de la vida urbana, escenario de las actividades cotidianas y de sus interferencias. La ciudad es un espacio de símbolos reconocidos o reconocibles día a día. Habitar la ciudad exige leer estos símbolos, lo que conduce a su apropiación como espacio de vida, espacio doméstico y espacio de aprovisionamiento, pero no sólo de bienes, sino también de ideas (De Certeau, 2010). De esta manera, comienza a desentramarse el camino hacia una perspectiva de abordaje del espacio urbano público más adecuada para una sociedad compleja y heterogénea como la actual, un espacio urbano público con un carácter más dinámico. Referirse a espacio simbólico, desde la mirada propuesta, es enfocar la perspectiva en lo intensamente arraigado a lo cotidiano, pero sometido al azar, al juego de los que participan en la vida urbana. El espacio urbano ya no puede ser, por lo tanto, abordado solo como lugar, sino más bien, como "(...) un tener lugar de los cuerpos que lo ocupan en extensión y en tiempo" (Delgado, 2007:13). Cotidianamente, organiza un orden social que es conformado por conductas cuasi predecibles. Son los sujetos los que hacen de la ciudad un lugar practicado y habitado (de constante fluctuación y movimiento), donde el puro acontecimiento los conecta con la arquitectura circundante que transitan a diario como escenario espacial.

El concepto de espacio puede asumirse como uno que liga lo mental y lo cultural, lo social y lo histórico. Si el espacio interviene en el modo de producción, cambia con dicho modo de producción y con las sociedades (Lefebvre, 2013). Las coaliciones peatonales como fiestas, kermeses, procesiones, manifestaciones, piquetes, reclamos sociales, o diversas intervenciones efímeras y transitorias, tienen lugar en el espacio urbano público como escenario y plataforma de acción, provocación e interacción. Estos acontecimientos no esperables, dislocados, desacomodados, anacrónicos y hasta inadecuados, como una especie de arritmia en lo cotidiano, alteran el anonimato de los sujetos y el sentido asumido y naturalizado que se tiene incorporado acerca de ese lugar intervenido. Sobre aquellas acciones que resultan imprevistas para el ciudadano cotidiano, particularmente las promovidas por agentes sociales pertenecientes al ámbito de las economías creativas, es sobre las que interesa investigar. Es decir, se buscó indagar en torno de aquella actividad efímera y transitoria que aparece donde no se esperaba que apareciera, lo que permite focalizar y recortar la visión sobre un detalle específico del espacio urbano, interrogándonos: ¿Puede la irrupción de la excepcionalidad en determinados espacios, como el del $\mathrm{CH}$, generar oportunidades para que surjan prácticas de habitar alternativas o disidentes a las actuales? ¿Puede el espacio público de la ciudad, y en particular el del $\mathrm{CH}$, expresar y fomentar prácticas y valores distintos e, incluso, opuestos a los dominantes? Desde la excepcionalidad de las prácticas mencionadas, ¿intervienen fuerzas reproductoras o también fuerzas y actos de resistencia o de diferenciación cultural? ¿Qué sucede en la ciudad actual para que la emergencia en la excepcionalidad de estas prácticas se exprese con mayor presencia e intensidad en el espacio urbano público hoy? ¿De qué se valen estas tácticas-intervenciones-acciones? ¿Qué proponen? ¿Qué buscan? ¿Qué generan y qué queda? ¿Qué impacto ocasionan? ¿Qué desafíos y retos enfrentan? ¿Podemos referirnos a estas espacialidades propuestas como modeladoras de valores culturales alternativos donde emergen nuevas formas híbridas de cultura-espacio pública?

Desde los estudios de la performance acentúan que para abordar el estudio de estas prácticas se debe considerar tanto el nivel performático como la operatividad performativa de las acciones (Menéndez, 2014). Es decir, se tiene que observar no solo qué son esas acciones urbanas creativas, sino también a qué niveles funcionan y, lo más importante, cómo se fundamentan en la cotidianeidad. La importancia de asentarse sobre tales nociones recae en que, de este modo, se abarcan otro tipo de fenómenos como la construcción de la subjetividad, de las identidades, de la producción y uso espacial, de los usos enunciativos del lenguaje, del activismo político o del uso del cuerpo en la vida cotidiana. Consecuentemente, estas consideraciones permiten también analizar estos fenómenos como procesos sociales.

El análisis de las acciones señaladas puede ser considerado desde la ingenuidad de la forma o de la imagen como un elemento más dentro del espacio de la ciudad, o bien pueden recuperarse las acciones desde la dinámica de un discurso social que construye comunitariamente sentidos para conformar una imagen de la ciudad. Observar las acciones y prácticas efímeras en el espacio urbano público solamente como expresiones artísticas creativas o marginales que degradan en parte o no la estética de la ciudad puede ser una opción de lectura. No obstante, lo que aquí se propone busca integrar relatos urbanos e imágenes a partir de encontrar relaciones, como también indagar sobre el movimiento y la inestabilidad que exponen estas 
prácticas al plantear un estado de límite y frontera entre hablar de la ciudad y construir, proponer y promocionar una imagen y vivencia de ella.

Al aproximarse al estudio de prácticas tácticas de carácter ascendente y creativas, asumidas como provoca/acciones urbanas, desarrolladas durante los últimos años en diversos espacios urbanos públicos del $\mathrm{CH}$ de la ciudad de Córdoba, se expone un despliegue en los límites de la complejidad. Al vincularse con paradigmas artísticos, urbanos, e incluso sociales, estas provoca/acciones generan complejos procesos de creación colectiva, de acción directa, de producción espacial, de solidaridades y redistribución de recursos de diversa índole. Estas prácticas han venido produciendo, cuestionando, inventando y reinventando continuamente lo público en la ciudad, diseminando distintos, diversos y hasta impensados modos de hacer $y$, sobre todo, concretando intereses y deseos de diversos agentes sociales urbanos individuales y colectivos que construyen y producen ciudad. Esto conlleva a ser un emergente objeto de estudio potencial y necesario de ser analizado, que poco ha sido aún explorado más allá de la promoción o divulgación de las acciones por sí mismas.

\section{LAS ACCIONES}

El abordaje del estudio de casos buscó dar cuenta sobre terreno específico de aquellas prácticas descriptas de manera teórica en instancias anteriores, para poder analizar y buscar a partir de ellas elementos y resultados empíricos que permitan verificar o no los supuestos previos e hipótesis planteadas. Se buscó poder analizar de manera crítica y reflexiva el proceso complejo que dio lugar al desarrollo de las prácticas a indagar, más que en la evaluación de resultados numéricos o cuantitativos.

Para la selección de los casos de estudio a analizar se realizó una búsqueda a partir de aquellas prácticas desarrolladas por agentes sociales asociados o relacionados al universo de las economías creativas como categoría emergente, posible de agrupar acciones y actores diversos y variados vinculados al desarrollo de prácticas creativas efímeras en la ciudad. Es importante en esta instancia volver a destacar que si bien el concepto y lo que conlleva tiene rasgos, características e implicancias posibles de ser discutidas, no se aborda dicha cuestión para esta investigación, sino que se lo asume como un universo posible de congregar y concentrar acciones, actores y el desarrollo de un determinado tipo de prácticas en el espacio. Además, es necesario volver a mencionar que, como tácticas, se seleccionaron aquellas consideradas en el espectro de lo artístico-creativo realizado por agentes pertenecientes al universo de las economías creativas, significando esto el recorte de uno de los variados posibles conjuntos de casos a analizar en el espectro de tácticas desplegadas sobre el espacio urbano público del $\mathrm{CH}$ de la ciudad de Córdoba, y entendiendo en dicho sentido que el universo de prácticas tácticas es mayor.

Para el análisis de casos se tomaron como guía y ejes de clasificación los tres niveles de interacción práctica referenciados en el modelo de círculos concéntricos para el ámbito de las economías creativas planteado por Throsby $(2001,2008)$, ya que se considera es en la actualidad la sistematización que mejor representa al concepto elegido, tanto por ser el de mayor empleo en los trabajos consultados como por la pertinencia de las clasificaciones asignadas. Además de la clasificación a partir de los círculos concéntricos, se seleccionaron acciones que, en su carácter efímero, al finalizar no dejaran rastros físicos en el espacio urbano público. En este sentido, acciones como grafitis o pinturas políticas se excluyeron para el análisis, sin dejar de reconocer que pertenecen a la clasificación de tácticas ascendentes y creativas, pero con otro nivel de implicación y relación con las preexistencias.

Debido a las limitaciones asumidas para esta investigación, solo se expondrá, para cada uno de los niveles establecidos, un caso considerado representativo y que haya sido ejecutado recientemente. Se asume para estas prácticas como factor común su desarrollo en el espacio urbano público junto a su condición de acción efímera y transitoria. Esta realidad conlleva a repensar la manera de reconstruir dichas prácticas desde su condición momentánea o esporádica para su posible estudio o análisis. Se considera de utilidad, en este sentido, la forma común que dicho tipo de acciones asumen para documentar o registrar su accionar efímero por medio del registro fotográfico y ediciones videográficas, características que las convierten en la única comprobación fidedigna de la intervención de los distintos actores, además de los testimonios subjetivos que cada uno de los actores implicados pueda aportar a partir de relatos o narraciones. 


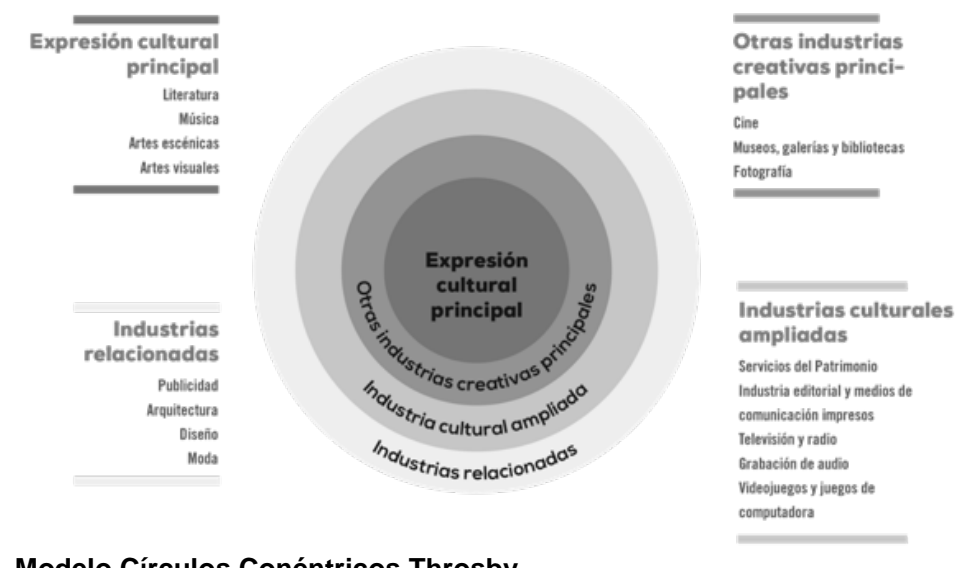

Modelo Círculos Conéntricos Throsby

Fuente: Throsby, Economics and Culture

Al ser acciones de carácter efímero y transitorio, se presenta como desafío el poder reconstruir el momento de la acción, como así también el proceso que dio lugar a su construcción. Se suma, además, que en el desarrollo de la práctica se conjugan no solo aspectos formales o físicos, sino también, aspectos subjetivos y vivenciales de acuerdo a lo que los diferentes actores implicados vivencien. Se propone para cada uno de los casos a estudiar leer el proceso en la construcción, elaboración y ejecución de la práctica, los actores implicados, el lugar donde se desarrolló, el impacto generado y el aporte realizado. Para realizar dicha lectura se utilizó como material, a partir del marco teórico elaborado, lo obtenido en entrevistas semi-estructuradas a los protagonistas que desarrollaron cada una de las prácticas, como así también la consulta de documentos, bibliografía o publicaciones referidas a dichas acciones, artículos periodísticos, junto a comentarios y críticas de especialistas como del público participante. Como guía para la exposición de los resultados en cada uno de los casos, y en el desafío de estructurar y sistematizar la información múltiple, se leyeron y analizaron las siguientes variables:

a. Presentación del caso: reseña del caso de estudio, justificación de la elección y exposición de los objetivos buscados.

b. Contexto: descripción del lugar y espacio de emplazamiento.

c. Proceso: construcción, elaboración y ejecución de la práctica.

d. Resultados: evaluaciones, mediciones de impacto o apreciaciones por parte de los autores como del público asistente.

e. Valoración: lectura y análisis de los aportes realizados.

f. Material: nominación de los documentos y recursos consultados y empleados para el análisis

Debido a la extensión para el presente trabajo solo se expondrá una síntesis de lo elaborado. La elección de los casos a estudiar y analizar para cada uno de los niveles se debe, en primer término, al grado de inclusión posible que conllevan, ya sea en actores, espacios y lugares asignados en la ciudad para la ejecución de las prácticas. Por otra parte, además de haber sido desarrollados en el $\mathrm{CH}$ de la ciudad, los tres casos abordan diversidad de actores implicados como escala y jerarquía en los lugares intervenidos. Además, se suma como característica y elemento común para la elección, el poder haber sido en parte partícipe en todas ellas como actor participante, como transeúnte que descubre estas prácticas al irrumpir la cotidianeidad del ritmo urbano. Finalmente se eligieron por ser también todas ellas ejecutadas en cercanía temporal al inicio de esta investigación (año 2013), pudiendo tener material posible de ser consultado para su análisis, ya sea bibliográfico, audiovisual, junto al recolectado desde la interacción o vinculación con los promotores de estas prácticas como de quienes participaron en ellas. A partir de la elección de casos, y desde el análisis, estudio y valoración de la muestra teórica precisada, se buscó como resultado la réplica o extensión de la teoría emergente. Parte de las relaciones establecidas como las fisuras y diferencias encontradas serán expuestas en las conclusiones.

\subsection{Nivel 1. Expresión Cultural Principal}

Caso de estudio: Ciudades Visibles

Autores: Proyecto BigBang Arte

Ubicación: plazoleta frente a la iglesia de la Compañía de Jesús

Año: Octubre, 2009

Síntesis: acción que buscó indagar en aspectos tales como la problemática vigente sobre el espacio donde se desarrolla la práctica, la relación habitante-ciudad-habitante y las lógicas cotidianas en el uso de la ciudad. La propuesta propone pensar la ciudad desde un universo de significados que pueden ser planificados o 
diseñados (estrategias); y junto a ello la dinámica, el movimiento, el tránsito, lo inquieto o inquietante, la aparición de coaliciones peatonales que pueden convertirse en manifestación, en expresión inesperada (tácticas); que pueden parecer un momentáneo estado de excepción y que, sin embargo, son la norma (pragmática) de lo urbano en lo cotidiano, expuesto en y a los actos y los usos frente a la forma (sintáctica y semántica) de la ciudad. Representan un espacio de búsqueda alternativo en la ciudad de Córdoba, aún poco explorado y experimentado, más allá de lo que el colectivo pueda ofrecer. Se destaca la vinculación con instituciones y diversos organismos para la difusión y concreción de las acciones, como así también la búsqueda en construir públicos heterogéneos que descubran maneras diferentes o distintas de vivir lo público en la ciudad. Su objetivo es activar imaginarios y vivencias urbanas distintas en quienes transiten sus acciones efímeras para vincularlos a redes culturales en la construcción de territorios en la ciudad.
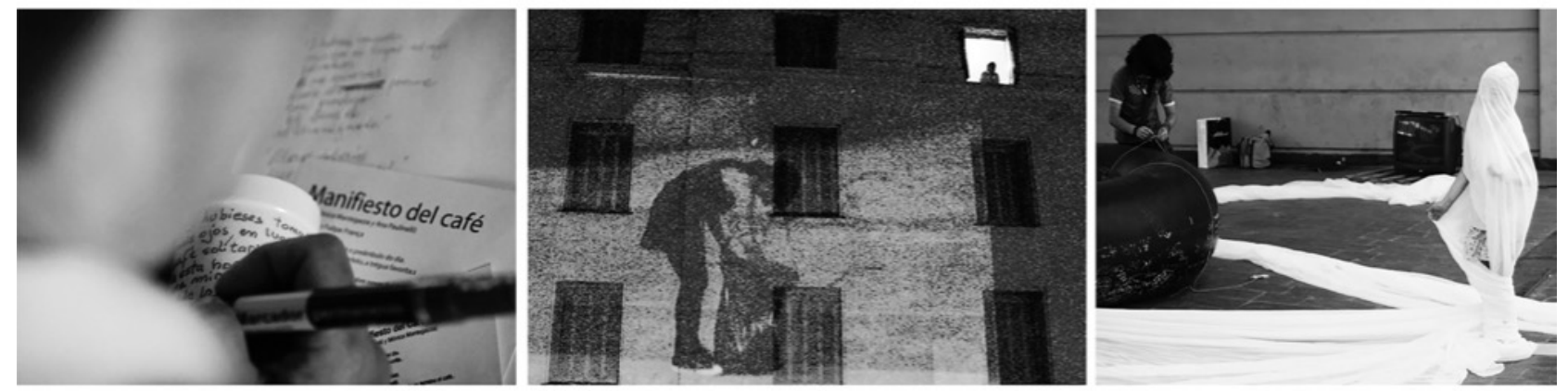

Distintas acciones realizadas en el ciclo Ciudades Invisibles

Fuente: Proyecto BiBang Arte

\subsection{Nivel 2. Industrias culturales}

Caso de estudio: ¡Afuera! Muestra Internacional de Arte Contemporáneo en Córdoba Autores: Centro Cultural España Córdoba

Ubicación: diversos espacios urbanos públicos del Centro Histórico de la ciudad de Córdoba

Año: Octubre, 2010

Síntesis: serie de acciones realizadas por distintos artistas en el contexto de una muestra internacional de arte. La muestra indagó intensamente la posibilidad de explorar el límite, la frontera de separación entre lo público y privado, e incluso la distinción entre adentro y afuera. Esto se evidenció en la multiplicidad y variedad de obras expuestas en los espacios urbanos públicos como acciones y sitios intervenidos. No obstante, cabe señalar que cada una de las obras fue realizada e ideada previamente pensando en sujetos determinados, con saberes y referencias específicas, los que no siempre concordaron con los que finalmente habitaron las obras, quitando cierto carácter y alguna de las veces pareciendo actuar la espontaneidad pretendida.

La escala de intervención en la ciudad que tuvo el evento fue destacada, significando un quiebre en la manera de intervenir desde el universo creativo de performance, instalaciones y distintos tipos de prácticas y dispositivos en el espacio urbano público cordobés. Se destaca además de la muestra la interacción con el público, no solo desde las obras propiamente desarrolladas, sino también desde la reflexión y la crítica en procesos diferentes planteados desde las conferencias y debates en el auditorio como en las residencias de artistas junto a otras instituciones como escuelas y distintos centros educativos. El rasgo más destacado del evento fue tal vez, aunque no el único, el de disponer desde una actitud efímera y transitoria un juego interactivo de acciones sobre el espacio urbano público donde exploraron e indagaron nuevas prácticas culturales sobre la plataforma de la ciudad.
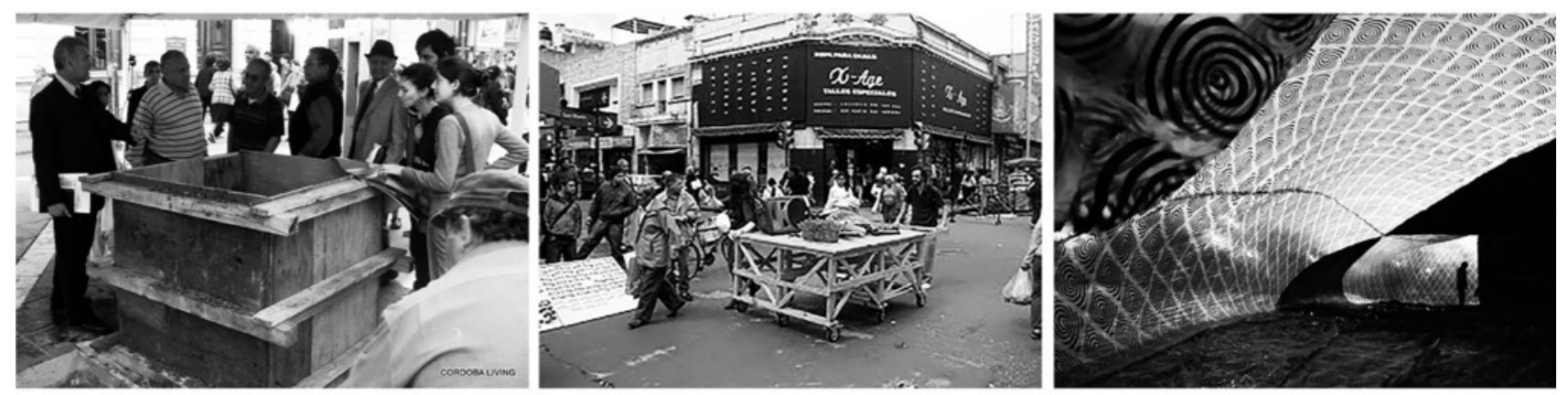

Acciones y encuentros desarrollados por distintos artistas durante el ciclo ¡Afuera! Fuente: Centro Cultural España Córdoba 


\subsection{Nivel 3. Industrias relacionadas}

Caso de estudio: Acción mutante. Indagaciones proyectuales en torno al espacio público Autores: Colapso

Ubicación: cruce del Bv. Arturo Illia y la Av. Poeta Lugones, Terminal de Ómnibus

Año: octubre, 2014

Síntesis: se buscó explorar el concepto de patrimonio en relación al espacio público, a partir de acciones que persiguieron indagar posibilidades y múltiples abordajes a partir de la realización de intervenciones temporales que provoquen la re-habitación y activación de espacios públicos degradados y residuales de la ciudad de Córdoba. La intervención permitió una relectura de lo inmaterial que co-habita lo tangible arquitectónico percibido a diario. Las intervenciones urbanas efímeras en esa óptica tienen la capacidad de alterar y reformular ese orden de sentidos originarios del espacio preexistente, resemantizándolo. La búsqueda y exploración del concepto patrimonio en relación al espacio urbano público, llevó al colectivo como a los actores participantes durante la práctica, a recorrer el espacio como una práctica lúdica, ubicándolos en una intersección entre el anonimato y el ser sospechosos. Ubicados en el margen, en la frontera que expone lo edificado, especialmente aquel asumido como patrimonio, en el umbral entre lo público y lo privado, en el medio de estas dos condiciones, se buscó no ya las relaciones de lectura que permiten comprender el espacio y el tiempo de la ciudad, sino descubrir en ella otros espacios que aún están allí por ser descubiertos.
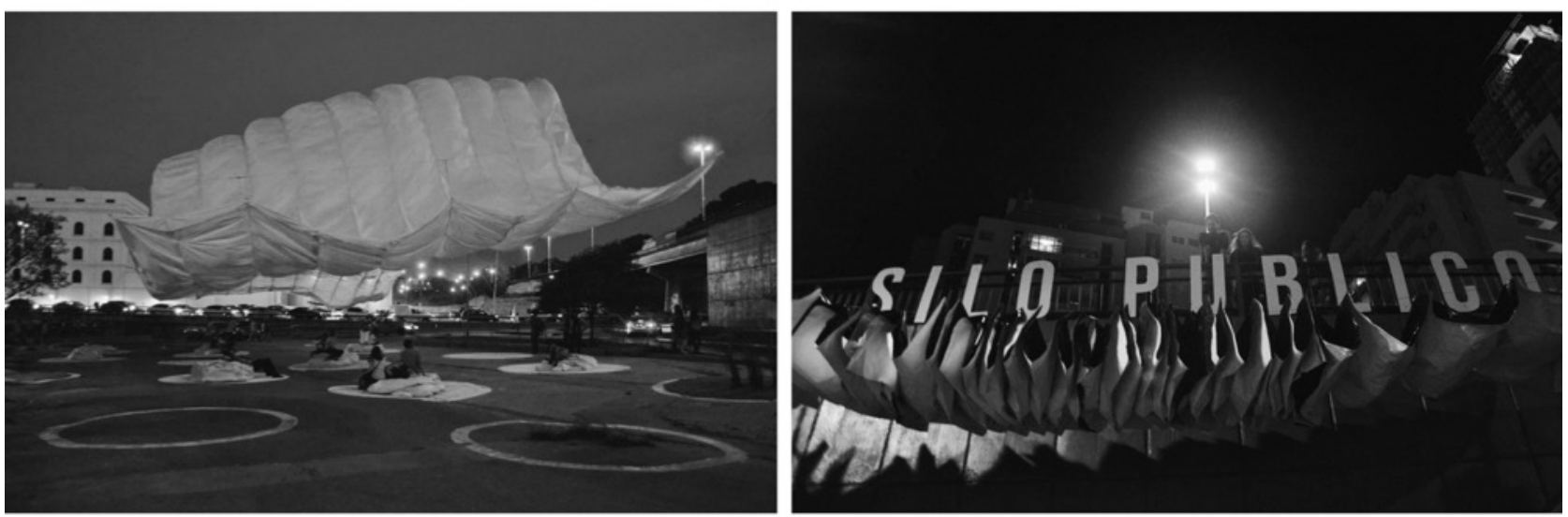

Nuevas espacialidades efímeras desarrolladas durante Acción Mutante Fuente: Colapso

\section{CONCLUSIONES}

A partir de los tres casos analizados, y comprendiendo que solo representan el recorte de un universo mayor, complejo y con otras posibilidades de análisis, las prácticas estudiadas respondieron en su accionar a un activismo político, apelaron a un cuestionamiento de la frontera entre lo que es y no es arte, entre lo público y lo privado, el adentro y el afuera. Jugaron con generar un shock en los transeúntes donde se esperaba que hubiera teatralidad, emplearon ciertas tecnologías para generar yuxtaposición de sentidos sobre un mismo escenario de la ciudad y optaron por el emplazamiento de monumentos efímeros, siluetas o imágenes para materializar hechos vividos socialmente. Ahora bien, ¿qué aportan las tácticas artísticas creativas al espacio urbano público de las estrategias que se expresan en las preexistencias? ¿Qué le permiten a la ciudad de las estrategias institucionalizadas?

Frente a la crisis global contemporánea, la actualidad se presenta como un momento de fragmentos donde se plantea el desarrollo de estas prácticas efímeras como posibilidad de construir umbrales frente a una ciudad de enclaves (Stavrides, 2016). Desde un planteo en la transdiciplinariedad artística y creativa habitada en cada una de las prácticas, en la hibridación entre lo público y lo privado junto con la liminalidad propuesta o la utilización y empleo del espacio urbano público como plataforma y escenario puramente del acontecimiento, estas prácticas colocaron acento en determinados aspectos atravesados por lo social, lo político, lo urbano y lo artístico creativo. Presentaron como resultado formas diversas de repensar el propio arte, pero también lo político y lo urbano. Al tratarse de acciones efímeras y fugaces, poder dar cuenta de ellas de algún modo es también preservarlas y prolongar su accionar transitorio. Conformaron en su excepcionalidad parte del modo de ser (extracotidiano) de la ciudad, visualizado y planteado desde otros modos de percibirla, entenderla o bien transitarla. 
Como afirmaba Lefebvre (2013), toda práctica social practica el espacio, lo produce, lo organiza y, solo puede hacerlo a través de esa herramienta con que sus componentes cuentan y que es fundamentalmente el cuerpo. Por lo tanto, como reflexión final, se puede sintetizar que son acciones que generaron una provocación en los lugares del habitar en cuanto alteraron el ritmo: de lo cotidiano, las memorias y los lugares urbanos.

Cotidiano: la rítmica permite leer el presente y el futuro (Han, 2015) a través de una suerte de partitura con repeticiones definitorias (Stavrides, 2016). En este sentido, la irrupción de prácticas diferentes a las habituales altera ese ritmo en una provocación, una búsqueda de intereses que se cruzan entre los personalesindividuales y los colectivos-sociales. Se generan en este sentido especies de umbrales (Stavrides, 2007; 2016), zonas intermedias en la que ámbitos supuestamente diferenciados (en términos espaciales, dentro y fuera; en términos jurídicos, la ley y la anomía) pierden sus márgenes y se diluyen uno en el otro. Demostraron en su accionar que buscan un despertar (principalmente, aunque no de manera exclusiva) a partir de lo visual sobre la ciudad cotidiana, como instante que irrumpe y rompe la falsa totalidad de percepción, alterando sus automatismos.

Memorias: las acciones analizadas partieron del reconocimiento del valor potencial que las preexistencias tienen en la ciudad. Alteraron la realidad del ser edificado (arquitectura) reconociendo su condición de preexistencia en cuanto se lo hizo a manera de ensayo, de búsquedas, o más bien de preguntas. A través de las experiencias analizadas, se observó cómo es posible revelar rincones y edificios de la ciudad de profunda carga simbólica, patrimonial y estética de los cuales existe muchas veces un desconocimiento en el andar cotidiano. Junto con ello, mediante el uso de ciertas tecnologías, también se experimentaron el carácter, rol y funcionalidad de sus límites, explorando su capacidad entre el adentro y el afuera y su posibilidad de ser soporte y parte de la obra transitoria, despertar la mirada y comenzar a interrogar, a indagar. Se invitó también, así a los transeúntes a descubrirse a sí mismos, como ciudadanos, vecinos y portadores de una herencia (la ciudad como patrimonio) que merece ser cuestionada colectivamente. El patrimonio, considerado desde una visión amplia y compleja, indefectiblemente se asume como aquello que heredamos y que, a su vez, de un modo u otro reconocemos al valorarlo y darle trascendencia. Dicha idea siempre se ajusta y actualiza en el tiempo y en las circunstancias de forma evidente y manifiesta. La creatividad de las provoca/acciones sobre las preexistencias no es la razón de ser de las mismas, no obstante, interesa y resalta por la actualización a partir de lo que son, cuentan y valen. Trayendo, en este sentido, nuevamente a la memoria e incorporándola a la reflexión sobre la contemporaneidad en relación al patrimonio edificado en el $\mathrm{CH}$ de la ciudad de Córdoba, resulta inquietante y atractivo el logro generado por las provoca/acciones al proponer pensar, experimentar, proyectar e imaginar actualizaciones creativas y consecuentes con el pasado y la conservación de las preexistencias. En este sentido, el valor de sumar a la memoria en el accionar de estas prácticas, importa como variable que, partiendo de asumir a la ciudad como patrimonio, implica como consecuencia asumir que algo debe cambiar al interior de las miradas sobre las preexistencias y su conservación, verificable tal cambio en el ajuste de precisiones conceptuales, metodológicas y operativas.

Lugares: generaron una (re)semantización de las preexistencias espaciales y edificadas desde una capacidad interpretativa doble, ya que la ciudad no se ocultó, sino que funcionó como escenografía, escenario, ser y parte de la acción. Se buscó crear espacios menos rígidos, ya sea por advertir algunas de las posibilidades inherentes a determinados lugares o porque crearon por sí mismas esas posibilidades que, en ocasiones, entran en confrontación directa con el uso y las regulaciones que tienden a definir determinados espacios. Se transformaron espacios para una acción que no era considerada como autorizada, institucionalizada o formalizada y para que tengan lugar en ellos encuentros creativos, imprevistos e inesperados, lo que en cierta manera colaboró a soltar o liberar esos espacios, a transformarlos en espacios de carácter intermedio. Su existencia, identificada como umbrales, depende de que sean real o virtualmente cruzados.

La palabra creatividad deriva del latín creare, que significa engendrar, producir, crear; crear es producir algo que no existe. El verdadero aporte en buscar provocar al ciudadano a partir de ciertas prácticas creativas y transitorias es, quizás, poder comenzar a pensar y crear una ciudad de ciudades, una ciudad de umbrales, en las que cada persona puede verse identificada dentro de la alteridad y, por lo tanto, dentro de su diferencia, donde se sienta y vivencie motivación y empatía para actuar con libertad y creatividad. Quizás solo tenemos que aprender a ser creativos con la ciudad, sus espacios y el patrimonio edificado, porque la ciudad, asumida como organismo vivo, debe ser vida, y la vida en su génesis es, ante todo, creación.

\section{BIBLIOGRAFÍA}

BAUMAN, Z. (2011). Tiempos líquidos Vivir en una época de incertidumbre. Buenos Aires: Tusquets Editores. CARRIÓN, F. (2008). Centro histórico: la polisemia del espacio público. Revista Centro-h, 2, 89-96. 
CARRIÓN, F. (ed.) (2001). La ciudad construida. Urbanismo en américa latina. Quito: Flacso

CUNNINGHAM, S., BANKS, J. \& POTTS, J. (2008). Cultural Economy: The Shape of the Field. In The Cultural Economy. En, Anheier, H \& Isar, Y. R. (eds). The Cultures and Globalization. Londres: SAGE Publications. DE CERTEAU, M. (2010). La invención de lo cotidiano I. Ciudad de México: Ed. Universidad Iberoamericana. DELGADO, M. (2007). Sociedades movedizas. Barcelona: Anagrama.

DI FELICE, M. (2012). Paisajes posurbanos. Córdoba: Ediciones del Copista.

GNEMMI, H. (2014). Sobre las capas de la memoria en el patrimonio edificado. Inédito.

GRAVANO, A. (2013). Antropología de lo urbano. Buenos Aires: UNCPBA.

GROYS, B. (2016). Arte en flujo. Buenos Aires: Caja Negra Editora.

HAN, B.-C. (2016). La sociedad de la transparencia. Burzaco: Herder.

HOWKINS, J. (2001). The creative economy. Londres: Penguin.

JOHNSON, S. (2003). Sistemas emergentes. Ciudad de México: Fondo de Cultura Económica.

LANGE VALDES, C. (2015). Comprender la Urbanidad. Revista Antropologías del Sur, 3, 137-154.

LATOUCHE, S. (2014). Límite. Buenos Aires: Adriana Hidalgo editora.

LEFEBVRE, H. (2013). La producción del espacio. Madrid: Capitán Swing.

LLAMAZARES, A. M. (2013). Del reloj a la flor de loto. Buenos Aires: Del nuevo extremo.

MENENDEZ, L. (2014). Performance y acción creativa en el espacio público. LIÑO. Revista Anual de Historia del Arte (20), 147-158.

PNUD-UNESCO (2013). Informe sobre la economía creativa. New York: Naciones Unidas,

REYNOSO, C. (2015). Complejidad y caos. Buenos Aires: Editorial Sb.

STAVRIDES S. (2016). Hacia la ciudad de umbrales. Madrid: Ediciones Akal.

THROSBY, D. (2008). Modeling the cultural industries. International Journal of Cultural Policy, 14 (3), 217232.

THROSBY, D. (2001). Economics and Culture. Cambridge: Cambridge University Press.

TORRES, A. C. (2003). Paradigmas e Tendências nos Estudos Urbano-Regionais Contemporâneos. En, C. Acuña y A. Riella (Comp.), Territorio, sociedad y Región. Montevideo: Universidad de la República.

WAGENSBERG, J. (2017). Teoría sobre la creatividad. Buenos Aires: Tusquets Editores. 